\title{
Contributions of Water and Total Nitrogen of Inflow Rivers to West Dongting Lake Linked to the Yangtze River Using Major Ion Tracing
}

\author{
Yingjie $\mathrm{Li}^{1}$, Lijing Wang ${ }^{1}$, Zebin Tian $^{1}$, and Hong $\mathrm{Li}^{1}$ \\ ${ }^{1}$ Chinese Research Academy of Environmental Sciences
}

May 14, 2020

\begin{abstract}
West Dongting Lake (WD) receives water from local rivers, the Yuan and Lishui Rivers, within the lake basin and is recharged by the Yangtze River outside the basin through three outfalls. Thus, water pollution control is more complicated in WD than in lakes disconnected from the Yangtze River. Here, major ion tracing which was a method rarely applied in the river-lake system was used to characterize the contribution of water and total nitrogen (TN) from the inflow rivers to WD, and 9 sampling sites in WD and its inflow rivers were investigated in December 2016 (the dry season, DS), April 2017 (the normal season, NS) and August 2017 (the wet season, WS). Na+ and Cl- were suitable tracer ions used in the ion tracing model to estimate the water and TN contributions from inflow rivers to WD. Results showed that the water and TN in WD who presented river and lacustrine phases were mainly contributed by local rivers rather than the three outfalls, in which the contribution of Yuan River was larger than that of Lishui River. However, the contribution rates of water and TN of the three outfalls to WD during WS reached above $20 \%$ and $30 \%$ respectively, indicating that the contribution of the three outfalls could not be ignored, in which the contributions of water and TN from Songzi outfall were higher than those from Taiping and Ouchi outfalls. Therefore, we suggest that the relevant departments should identify key river management targets during different water periods, implement refined management over water pollution in WD, and prioritize the pollutant input of Yuran River and Songzi outfall (especially during WS).
\end{abstract}

\section{Contributions of Water and Total Nitrogen of Inflow Rivers to West Dongting Lake Linked to the Yangtze River Using Major Ion Tracing}

Yingjie Li ${ }^{1}$, Lijing Wang ${ }^{1, *}$, Zebin Tian ${ }^{2}$, Hong Li $^{1}$

${ }^{1}$ Operation Management Department of National Joint Research Center for Yangtze River Conservation, Chinese Research Academy of Environmental Sciences, No. 8 Dayangfang, Beiyuan Road, Chaoyang District, Beijing 100012, P. R. China.

2 National Engineering Laboratory of Lake Pollution Control and Eco-remediation Technology, Chinese Research Academy of Environmental Sciences, No. 8 Dayangfang, Beiyuan Road, Chaoyang District, Beijing 100012, P. R. China.

* Corresponding author: Lijing Wang (wanglj@craes.org.cn).

E-mail addresses of co-authors: lijj01@craes.org.cn (Yingjie Li), tianzebin@hotmail.com (Zebin Tian), lihong927@hotmail.com (Hong Li)

\section{Running title}

Contributions of Inflow Rivers to West Dognting Lake 


\section{Acknowledgments}

This research was funded by the National Science Fund for Distinguished Young Scholars of China (51609225), the Follow-up Work Project of the Three Gorges (2017HXXY-05) and the National Key Technologies Research and Development Program of China (2017YFC0404702). We are very grateful to the reviewers for their constructive comments to help improve the previous manuscript.

\section{Hosted file}

Main text file-HP.docx available at https://authorea.com/users/322001/articles/451124contributions-of-water-and-total-nitrogen-of-inflow-rivers-to-west-dongting-lake-linkedto-the-yangtze-river-using-major-ion-tracing

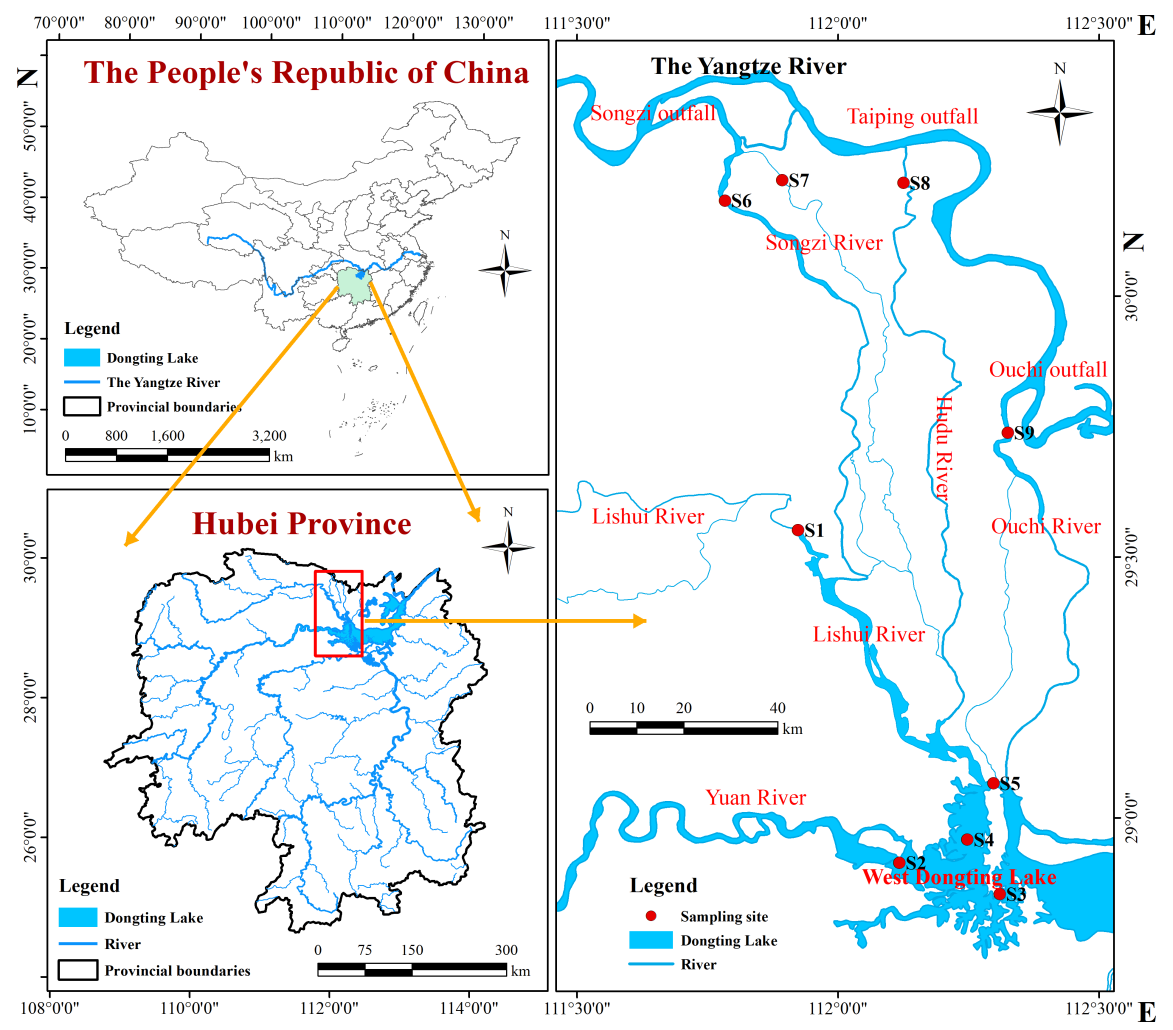



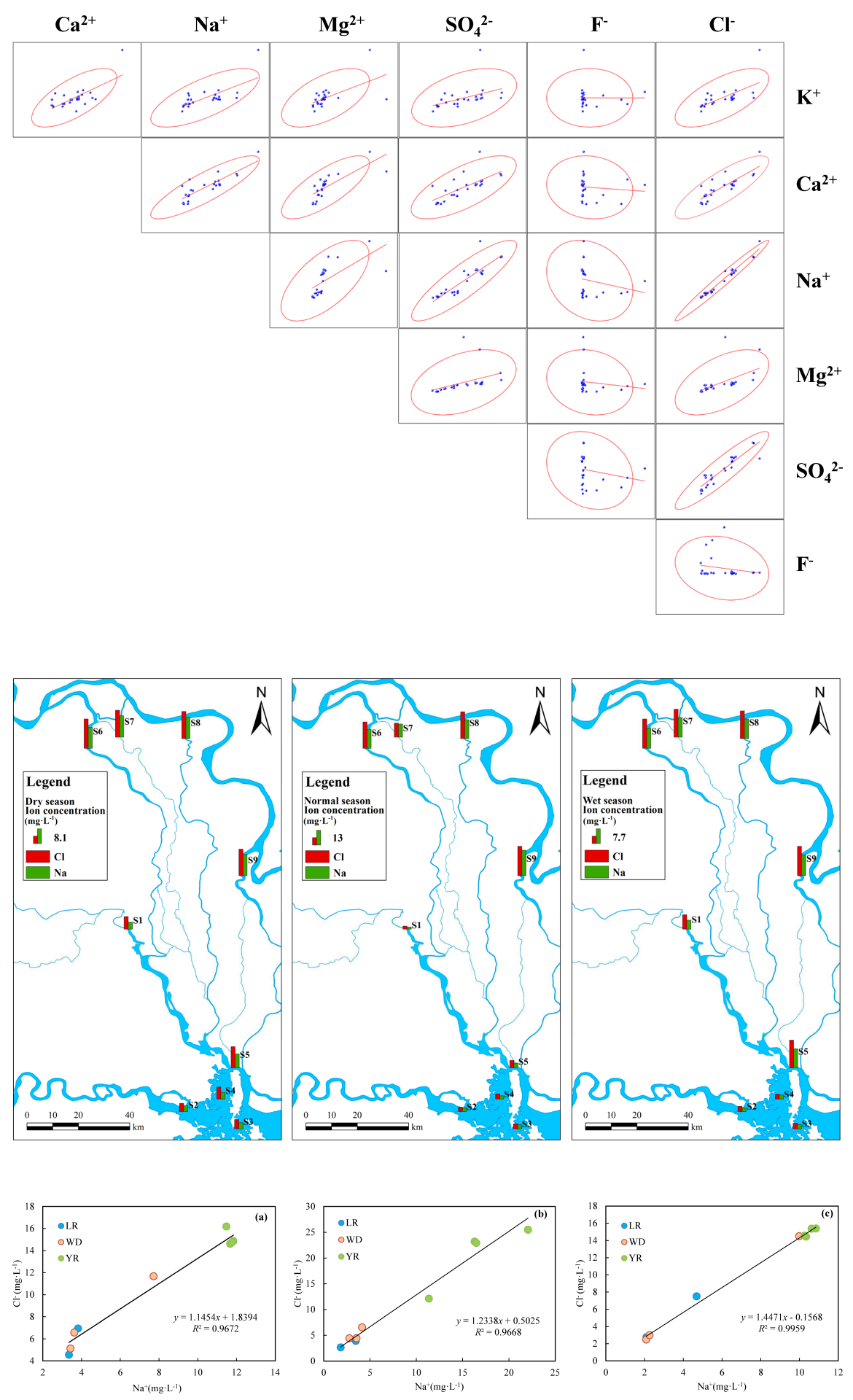


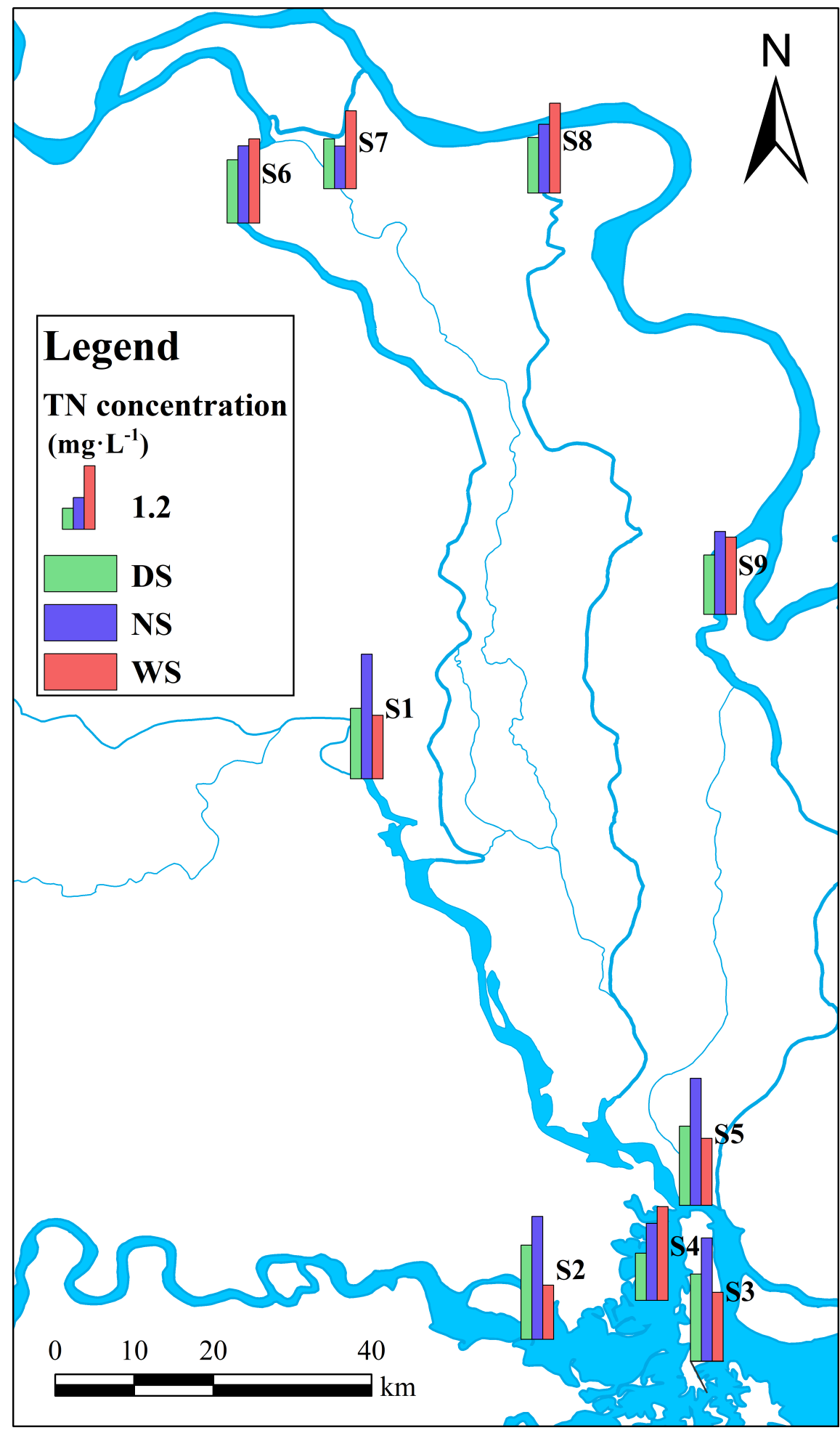



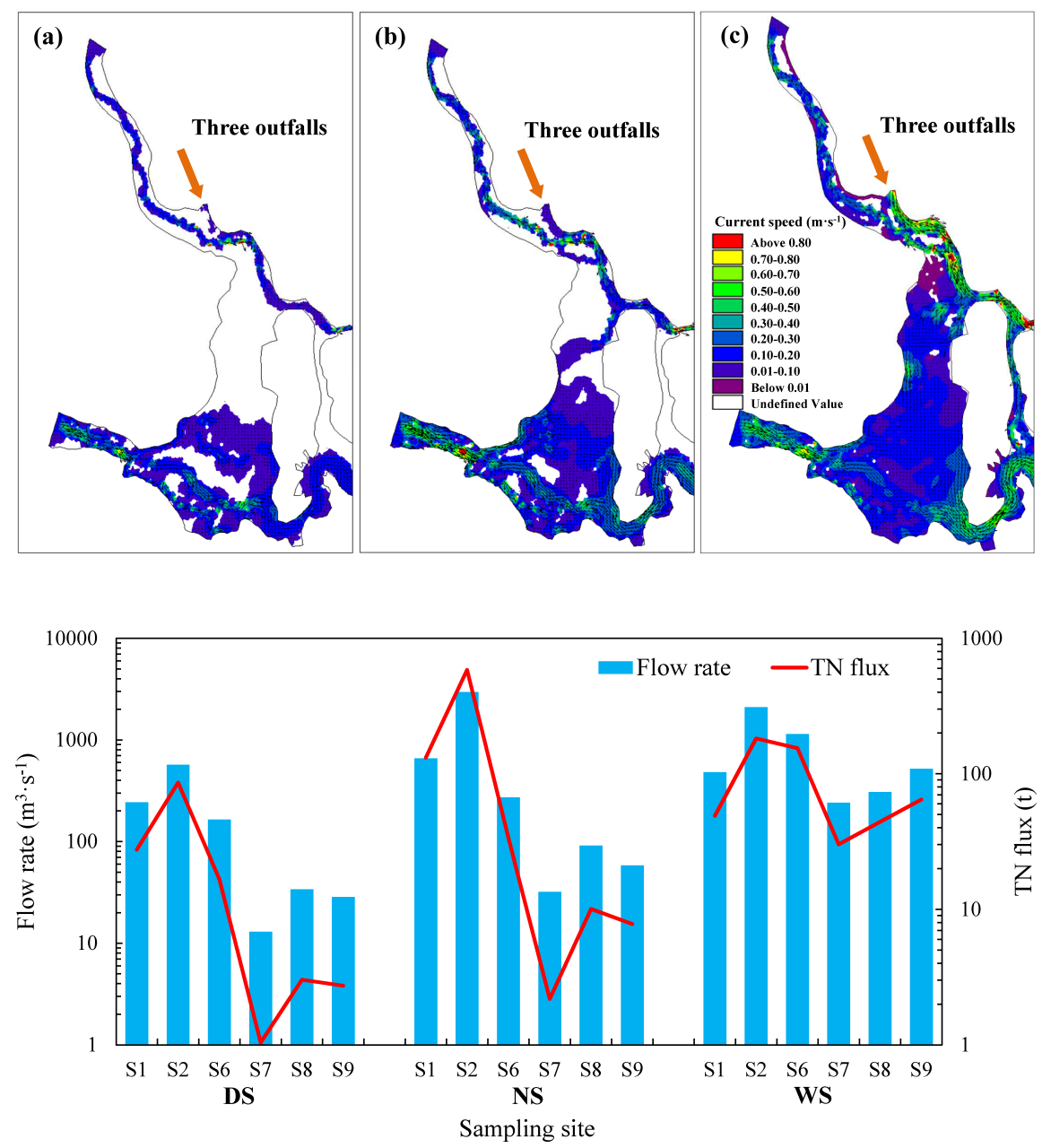